\title{
BREAST LUMP- A CLINICOPATHOLOGICAL STUDY
}

\author{
Yogesh Kumar Yashaswi', Pawan Kumar Jha², Pradeep Jaiswal', Vibhuti Bhushan', Krishna Gopal ${ }^{5}$
}

${ }^{1}$ Senior Resident, Department of Surgery, IGIMS, Patna.

${ }^{2}$ Additional Professor, Department of Surgery, IGIMS, Patna.

${ }^{3}$ Assistant Professor, Department of Surgery, IGIMS, Patna.

${ }^{4}$ Associate Professor, Department of Surgery, IGIMS, Patna.

${ }^{5}$ Associate Professor, Department of Surgery, IGIMS, Patna.

\section{ABSTRACT}

\section{BACKGROUND}

Breast lumps are showing a rising trend nowadays. Heightened anxiety associated with breast lump and its classification into benign and malignant is necessary. Seeing the burden of disease and rising trend of malignancy, our study aimed to document the spectrum of breast lump at Indira Gandhi Institute of Medical Sciences, Sheikhpura, Patna.

Aims and Objectives- Breast lumps are quite common, but the principal issue is differentiating malignant from the benign subgroups. The determinants of histologic diagnosis are multifactorial, ranging from environmental, genetic to sex and age-related factors. This study aimed to document the spectrum of breast lumps in our environment.

\section{MATERIALS AND METHODS}

This is a descriptive prospective analysis of consecutive breast lumps biopsied at Indira Gandhi Institute of Medical Sciences, Sheikhpura, Patna between December 2015 and November 2016. The data were analysed using statistical package for social sciences (SPSS) version 22.0.

\section{RESULTS}

A total of 200 patients with 220 breast lumps were seen, 198 females and 2 males giving male: female ratio of 1: 99 . The ages of the patients ranged between 16 - 82 years with a mean of 37.0 +/- SD 13.0. Majority (59.6\%) of the patients had benign lumps. Fibroadenoma was the commonest (35\%), followed closely by invasive ductal carcinoma (14.4\%) and then fibrocystic change (5\%). The occurrence of breast cancer was strongly age-related, being 1 in 5 biopsies at 20 - 29 years and 3 in 5 biopsies at 40 - 49 years' age groups. Over two-third patients with breast cancers were premenopausal.

\section{CONCLUSION}

Most patients with breast complaints present with lumps and majority are benign, fibroadenoma being the commonest histology. Occurrence of breast cancer is strongly age-related with majority of cancer patients presenting late.

\section{KEYWORDS}

Breast, Clinicopathology, Lumps, Fibroadenoma.

HOW TO CITE THIS ARTICLE: Yashaswi YK, Jha PK, Jaiswal P, et al. Breast lump- a clinicopathological study. J. Evolution Med. Dent. Sci. 2017;6(71):5023-5026, DOI: 10.14260/Jemds/2017/1092

\section{BACKGROUND}

Globally, breast diseases are showing a rising trend and as a result there is considerable interest in the clinicopathological studies of breast masses in various populations. ${ }^{1,2}$ In recent decades, gains of life expectancy from industrialisation have changed previous trends of disease in developing nations, creating a shift from diseases of pestilence and infections to those of cancers, trauma, cardiovascular disease and mental illness. ${ }^{3,4}$ Regional heterogeneity highlights the importance of understanding local burden of diseases and setting goals and targets, taking such patterns into account. ${ }^{3}$ Published data indicate that the rate of diagnosis of breast diseases has increased worldwide due to recent increase in awareness campaigns, greater availability of diagnostic and screening facilities and establishment of dedicated breast clinics. ${ }^{5-8}$

Financial or Other, Competing Interest: None.

Submission 31-07-2017, Peer Review 22-08-2017,

Acceptance 29-08-2017, Published 04-09-2017.

Corresponding Author:

Dr. Vibhuti Bhushan,

Associate Professor,

Department of Surgery, IGIMS, Patna.

E-mail: drvibhuti.bhusan@gmail.com

DOI: $10.14260 /$ jemds/2017/1092
The finding of a breast change in a woman's breast is usually accompanied by inordinate anxiety and reactions from the patient and her family.7,8 Because such change has a variable spectrum of presentations and pathological backgrounds, modern acceptable practice requires a stepwise diagnostic approach involving clinical, radiological and pathological assessments.5,7 Nevertheless, studies have shown that combined diagnostic information from clinical and pathological evaluation yields satisfactory diagnostic accuracy.5,9

The vast majority of referred patients with breast disorders present with breast lumps and receive benign diagnosis when subjected to histopathological examination. $7,8,9-11$

Results from many published studies reveal that breast cancer is the leading female malignancy in the world. It is against this background that the usual management of a palpable breast mass is based on the assumption that the mass is cancerous until proven otherwise. ${ }^{8}$ The need for proper evaluation of breast lumps is further emphasised by the occurrence of a subset of benign breast lesions categorised as proliferative breast diseases.8,12-14 These variants confer increased risk of progression to malignancy and their histologic diagnosis mandates mammographic surveillance even after excision.8,9,12-14 Similarly, the relative 
risk of invasive breast cancer is higher in women with complex fibroadenomas and remained elevated for decades after diagnosis. ${ }^{13,14}$ This risk further increases in patients with concomitant family history of breast cancer.

Data on breast diseases are scanty in our setting despite the recent global clamour for increased awareness campaigns in different populations. ${ }^{1,8}$ Available data generated from similar surveys on breast diseases from other populations provided formidable opportunities for knowledge of the disease spectrum, counselling, intervention strategies, advocacy for breast health programs and screening for early detection of breast cancers. ${ }^{15}$ The aim of this study was to analyse the spectrum of presentations and pathology of breast lumps at Indira Gandhi Institute of Medical Sciences, Sheikhpura, Patna.

\section{MATERIALS AND METHODS \\ Design and Settings}

This is a descriptive prospective study of patients with palpable breast lumps seen at Indira Gandhi Institute of Medical Sciences, Sheikhpura, Patna between December 2015 and November 2016.

\section{Patients}

All consecutive 200 patients with histology reports of breast biopsies were included. Patients without discretely palpable breast lumps and those who failed to give consent for biopsies were excluded. All the patients were seen and interviewed by a general surgeon in General Surgery at the surgical outpatient department of the hospital. Records of socio-demographic and relevant clinical data of each patient were obtained and entered into a standard proforma. Clinical diagnosis of benign or malignant breast lump after comprehensive history and physical examination was made. Radiological evaluation was not routinely done, but done only whenever required.

Basic investigations like haemoglobin level and urinalysis were routinely requested and their results recorded. Focused tests like chest and spine $\mathrm{x}$-rays, abdomino-pelvic ultrasound and liver function tests were reserved for those with clinically suspicious malignant lesions or co-morbidities. The method of biopsy used was either open (excision and incision) or tru-cut needle biopsies depending on size and clinical parameters at presentation. Majority of the patients had their biopsies under local infiltrative anaesthesia using 5 - $20 \mathrm{~mL}$ of $0.5 \%$ xylocaine in double dilution. Fewer patients required general anaesthesia.

Circumareolar followed by circumferential incisions were mostly used for oncoplastic purposes. Diathermy dissection was adopted in majority of cases to enhance haemostasis. Combined sharp and blunt dissection was used for tissue retrieval. For excision biopsies, passive drains were inserted in few cases with extensive dissection. Majority of skin incisions were closed with subcuticular stitches using Vicryl 2/0; others were executed with nylon 2/0 interrupted suturing. The resection specimens were preserved with $10 \%$ formal saline, labelled and sent to histopathology laboratory accompanied with detailed and completed histology form. Majority of the biopsies were performed on day case basis. One pathologist reported all the slides.

\section{Statistical Data Analysis}

Statistical data analysis was done using statistical package for social sciences (SPSS) software version 22.0 (IBM, USA 2015).
Chi-square test was used to determine the P-values for categorical variables with a P-value of less than 0.05 considered to constitute a statistically significant difference.

\section{RESULTS}

A total of 200 patients with biopsy confirmed breast lumps were enrolled in the study. The ages of the patients ranged from 16 - 82 years with a mean of $37.0+/-$ SD 13.0 .

There were 198 females and 2 males giving male-tofemale ratio of 1: 99. Among female patients 118 (59.6\%) were having benign breast lump and rest were having malignant breast lump. One of two males had benign lump and one had malignancy. Overall ratio of male-to-female benign and malignant tumour are 1: 60 and 1: 40 respectively. Of 198 females 50 was nulliparous, 148 had parity that ranged from $1-5$.

A total of 220 lumps in 200 patients were evaluated. On right side, 90 lumps were recorded out of which 80 were solitary (from 80 patients) and 10 were multiple from 2 patients giving a total of 82 patients. On left side, a total of 130 lumps were encountered; 100 lumps on left side were solitary from 100 patients and rest 30 were multiple found in 18 patients giving a total of 118 patients. This gives bilateral to unilateral ratio of breast lump as $1: 4.5$. No patients with multiple or bilateral lumps had different histopathological diagnosis. Duration of symptoms before presentation ranged from 4 days to 15 years with a mean of $2.8+/$ - SD 2.3 .

Out of 200 patients, 30 patients discovered the breast lump by breast self-examination (BSE); 160 (80\%) patients came to know about breast lump through an accidental discovery, $2(1 \%)$ patients had their breast lump accessed by their spouses and rest 8 patients (4\%) were discovered by their doctors.

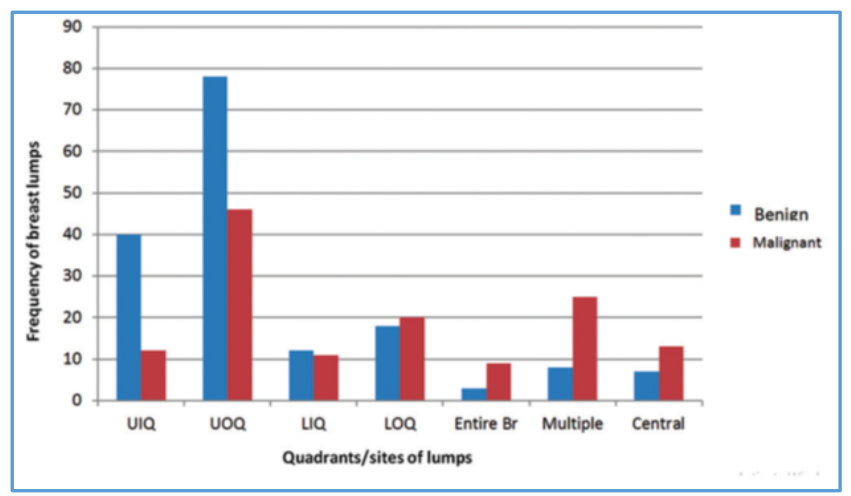

Figure 1. Graphical representation of distribution of Breast Lumps in the various quadrants/sites. UIQ = Upper inner quadrant; UOQ = Upper outer quadrant; LIQ = Lower inner quadrant. $L O Q=$ Lower outer quadrant; Entire $B r=$ Entire breast; Multiple= Multiple quadrants; Central= Central area

\begin{tabular}{|c|c|c|}
\hline Histological Diagnosis & Frequency & Percentage \\
\hline Fibroadenoma & 71 & $35.5 \%$ \\
\hline Fibrocystic disease & 20 & $10 \%$ \\
\hline Benign phyllodes & 20 & $10 \%$ \\
\hline Duct ectasia & 9 & $4.5 \%$ \\
\hline Chronic mastitis & 10 & $5 \%$ \\
\hline Granular cell tumour & 1 & $0.5 \%$ \\
\hline Reactive intramammary LN & 1 & $0.5 \%$ \\
\hline Neurofibromas & 1 & $0.5 \%$ \\
\hline Gynaecomastia & 1 & $0.5 \%$ \\
\hline Lactating adenomas & 1 & $0.5 \%$ \\
\hline
\end{tabular}




\begin{tabular}{|c|c|c|}
\hline Lipomas & 1 & $0.5 \%$ \\
\hline Invasive ductal carcinomas & 29 & $14.5 \%$ \\
\hline Invasive lobular carcinomas & 9 & $4.5 \%$ \\
\hline Medullary carcinoma & 5 & $2.5 \%$ \\
\hline Ductal carcinoma in situ & 2 & $1 \%$ \\
\hline Papillary cancer & 9 & $4.5 \%$ \\
\hline Mucinous cancer & 5 & $2.5 \%$ \\
\hline Burkitt's lymphoma & 5 & $2.5 \%$ \\
\hline \multicolumn{2}{|c|}{ Table 1. Histopathological types of Breast Lump } \\
\hline
\end{tabular}

\begin{tabular}{|c|c|c|c|c|c|}
\hline \begin{tabular}{c|} 
Clinical \\
Parameters
\end{tabular} & $\begin{array}{c}\text { Fibroadeno } \\
\text { mas }\end{array}$ & $\begin{array}{c}\text { Fibrocystic } \\
\text { Changes }\end{array}$ & Cancer & Others & $\begin{array}{c}\text { Total } \\
(\%)\end{array}$ \\
\hline \multicolumn{6}{|c|}{\begin{tabular}{l|l|l|} 
Complaints & & \\
\end{tabular}} \\
\hline Lump alone & 69 & 18 & 43 & 40 & $\begin{array}{c}170 \\
(85 \%)\end{array}$ \\
\hline Lump + pain & 2 & 2 & 1 & 5 & $\begin{array}{c}10 \\
(5 \%)\end{array}$ \\
\hline Ulcer + pain & 0 & 0 & 20 & 0 & $\begin{array}{c}20 \\
(10 \%)\end{array}$ \\
\hline Pain alone & 0 & 0 & 0 & 0 & $\begin{array}{c}0 \\
(0 \%)\end{array}$ \\
\hline \multicolumn{6}{|l|}{ Biopsy type } \\
\hline Excision & 70 & 20 & 10 & 44 & $\begin{array}{c}144 \\
(72 \%)\end{array}$ \\
\hline Incision & 1 & 18 & 24 & 1 & $\begin{array}{c}44 \\
(22 \%)\end{array}$ \\
\hline Trucut & 0 & 2 & 30 & 0 & $\begin{array}{c}32 \\
(16 \%)\end{array}$ \\
\hline \multicolumn{6}{|l|}{ Size $(\mathrm{cm})$} \\
\hline$<5 \mathrm{~cm}$ & 68 & 20 & 10 & 40 & $\begin{array}{c}138 \\
(69 \%)\end{array}$ \\
\hline$>5 \mathrm{~cm}$ & 3 & 0 & 54 & 5 & $\begin{array}{c}62 \\
(31 \%)\end{array}$ \\
\hline \multicolumn{6}{|l|}{$\begin{array}{c}\text { Axillary } \\
\text { node }\end{array}$} \\
\hline Present & 1 & 0 & 64 & 5 & $\begin{array}{c}70 \\
(35 \%)\end{array}$ \\
\hline Absent & 70 & 20 & 0 & 40 & $\begin{array}{c}130 \\
(51.5 \%)\end{array}$ \\
\hline
\end{tabular}

\section{DISCUSSION}

Heightened anxiety associated with breast cancer diagnosis causes many patients with breast disease to attend specialist surgical clinics irrespective of their age, sex or presenting complaints. ${ }^{7,8}$ Majority of patients with breast disease at our locality within the study period are relatively young females presenting with palpable lumps and having a preponderance of benign disease. This breast disease pattern conforms with reports from other populations. $8,9,11$ The percentage of benign breast disease $(59.6 \%)$ recorded in this study is in common agreement with a figure of $58.8 \%$ reported in Sokoto, 16 Nigeria.

The growing rates of benign breast disease in the developing communities of the world have important epidemiological and clinical implications. Reports culled from western literature implicate premenopausal status, family history of breast cancer, delayed age at first live birth $(>25$ years) and low parity with increased risk of progression to invasive cancer in women biopsied for benign breast disease.

We found that majority (88.2\%) of women with benign lumps are premenopausal, expressing yet greater concern for invasive cancer risk in young women in these populations.

The histologic types of breast cancer reported in this study conform with data from previous studies in Africa $7,8,9,11$ and Pakistan.2,10 The frequency of invasive ductal cancer among cancer cases in this study $(14.5 \%)$ is not in consonance with figures documented in Sokoto ${ }^{16}$ (76.2\%), Nigeria and Yemen ${ }^{17}$ (86.6\%). Similar results were noted by Ellis $^{18}$ from a referral hospital in London. This perhaps highlights the fact that the differences in the clinical profile of breast cancer in India and western economies are not due to histologic types, but may be related to tumour biology, delay in presentation, poverty and socio-cultural practices. Indeed, evidence from the emerging breast cancer epidemic in the developing nation shows that the current beliefs about hormone receptor subtypes of breast cancer in them is probably not systematically different from the pattern in other populations of developed nations after adjusting for factors like age and that the reported differences are related to poor tissue handling and laboratory processing practices.

In our study, 71 patients out of 200 were found to be diagnosed histologically as the fibroadenoma constituting majority of the cases. They constitute approximately $35 \%$ of total patients. The data found in our study is much lower than the datas of studies done in some African subcontinents. This difference can be attributed due to difference in study protocols such as difference of race, age and presentation.

Invasive ductal cell carcinomas is seen in 29 patients, which constitute $14.5 \%$ of cases. Invasive ductal carcinoma (IDC) is also known as infiltrating ductal carcinoma, is cancer that began growing in the duct and has invaded the fatty tissue of the breast outside the duct. It can spread to other parts of body as well.

Fibrocystic disease in our study is seen in 20 patients, constituting $10 \%$ of patients. Fibrocystic breast disease is a noncancerous condition, in which woman has painful lumps in her breast. According to literature, almost $50 \%$ of women will develop fibrocystic breast disease at some point in their lives. Redness on breast, nipple indentations or flattening, and certain types of discharge may be sign of breast cancer.

Benign phyllodes tumour constitute 20 patients in our study, which constitute $10 \%$ of cases. Benign phyllodes tumour is hard and can appear in supportive tissue (Stroma) of the breast. It is a benign breast condition thought to develop naturally as breast ages and changes. Once formed a phyllodes tumour may grow quite quickly and quite large. Sometimes, this can cause skin over the area to look red (Inflamed).

The rarity of the minor breast tumours recorded in this study (Phyllodes tumour, duct ectasia, gynaecomastia) has previously been reported and agrees with data from Maiduguri $^{7}$ and Nnewi ${ }^{7}$ both in Nigeria and Ghana. ${ }^{9}$ Two striking observations were made with these uncommon breast tumours. A single case of duct ectasia with axillary lymph nodes was misdiagnosed as cancer by clinical and ultrasound methods, but histology confirmed its benignity. Second, a benign phyllodes tumour misdiagnosed as fibroadenoma even after tru-cut biopsy was correctly typed after histologic examination of the entire resected specimen.19,18 The clinical value of these observations lies on the differences in their surgical management and expresses the imperativeness of step-wise diagnostic approach for dominant breast masses.

\section{CONCLUSION}

The occurrence of different breast lumps in our environment has strong links with the ages and menstrual status of the 
patients. The benign lumps are commoner in younger premenopausal patients, while breast cancer incidence increases with age and peaks around 40 - 49 years' group. Enormous concern over cancer risk for the proliferative benign lesions exists since regular mammographic screening programme is still in abeyance at peripheral health units. Breast cancer campaign in our environment remains inadequate, because majority of the patients with breast cancer in this study presented with advanced disease. The need for a dynamic national program on breast cancer awareness campaign and screening is salutary if any meaningful outcomes are desired.

\section{REFERENCES}

[1] Jeje EA, Mofikoya B0, Oku YE. Pattern of breast masses in Lagos: a private health facility review of 189 consecutive patients. Nig Q J Hospital Med 2010;20(1):38-41.

[2] Siddiqui MS, Kayani N, Gill MS, et al. Breast diseases: a histopathological analysis of 3279 cases at a tertiary care centre in Parkistan. J Park Med Assoc 2003;53(3):94-7.

[3] Thomas GW, Scott ER, Katherine DT, et al. An estimation of the global volume of surgery: a modeling strategy based on available data. Lancet 2008;372(9633):139-44.

[4] Akarolo-Anthony SN, Ogundiran TO, Adebamowo CA. Emerging breast cancer epidermic: evidence from Africa. Breast Cancer Res 2010;12(Suppl 4):S8.

[5] Tong FL. The role of fine needle aspiration cytology and needle core biopsy in the diagnosis and management of breast cancers. Cytopathology 2007;1(6):8-12.

[6] Anyanwu SN. Temporal trend in breast cancer presentation in the third world. J Exp Clin Cancer Res 2008;27:17.

[7] Egwuonwu OA, Anyanwu SNC, Chianakwana GU, et al. Breast lumps in Nnamdi Azikiwe university teaching hospital, Nnewi, Nigeria: a 5 year review. Nigerian Journal of Surgery 2009;15(2):6-9.
[8] Njeze GE. Breast lumps: a 21-year single center clinical and histological analysis. Niger J Surg 2014;20(1):38-41.

[9] Ohene-Yeboah MO. An audit of excised breast lumps in Ghanaian women. WAJM 2005;24(3):252-5.

[10] Aslam HM, Saleem S, Shaikh HA, et al. Clinico pathological profile of patients with breast diseases. Diagnostic Pathology 2013;8:77.

[11] Irabor DO, Okolo CA. An audit of 149 consecutive breast biopsies in Ibadan, Nigeria. Park J Med Sci 2008;24(2):257-62.

[12] Hartmann LC, Sellers TA, Frost MH, et al. Benign breast cancer and the risk of breast cancer. New England J Med 2005;353(3):229-37.

[13] Guray M, Sahin AA. Benign breast diseases: classification, diagnosis and management. Oncologist 2006;11(5):435-49.

[14] Dorjgochoo T, Deming SL, Gao YT, et al. History of benign breast disease and risk of breast cancer among women in China: a case controlled study. Cancer Causes Control 2008;19(8):819-28.

[15] Anderson BO, Braun S, Lim S, et al. Early detection of breast cancer in countries with limited resources. Breast J 2003;9(2):S51-9.

[16] Isah RT, Sahabi SM, Muhammad AT, et al. Analysis of female breast biopsies in usman danfodiyo university teaching hospital (uduth), sokoto, nigeria: a ten year retrospective study. IORS Journal of Dental and Medical Sciences 2013;8(4):55-8.

[17] Kumar R. A clinicopathologic study of breast lumps in Bhairahwa, Nepal. Asian Pac J Cancer Prev 2010;11(4):855-8.

[18] Olu-Eddo AN, Enoghama U. Benign breast lesions in an African population: a 25-year histopathological review of 1864 cases. Niger Med J 2011;52(4):211-6.

[19] Shirley SE, Mitchell DI, Soares DP, et al. Clinicopathologic features of breast diseases in jamaica: findings of the jamaican breast disease study 2000-2002. West Indian Med J 2008;57(2):90-4. 